\title{
Analysis of Grammatical Errors in Written Texts by Latvian Students of Chinese as a Foreign Language
}

\author{
Qiongzi Wang \\ Huanggang Normal University, PRC, China
}

Doi: 10.19044/llc.v7no2a1 $\quad$ URL:http://dx.doi.org/10.19044/llc.v7no2a1

\begin{abstract}
The main goal of this paper is to find out the most wide-spread syntactical errors, their causes and to put forward new, useful teaching strategies. From the perspective of the Error Analysis (EA), the research objects of this article are errors in the learning process of Chinese as a Foreign Language (CFL) by Latvian students. Main tasks were: to collect examples of four types of errors (i.e. wrong word order, wrong usage of words, wrong addition of words and wrong omission of words), to analyze reasons for these errors; to gather opinions via questionnaires in order to understand the motivation of students and to learn their, strengths and weakness while learning the Chinese language. The result of the research shows that errors of wrong sentence structure and wrong usage of words are the most wide-spread. There are six types of common errors among collected data. A direct transfer of the mother tongue and a generalization of knowledge in teaching and learning are the major causes for such errors. Therefore, more attention should be paid to the prediction of errors, the correction of errors and the selfcorrection.
\end{abstract}

Keywords: Chinese as a Foreign Language, Grammar, Error Typologies, Error Analysis.

\section{Introduction}

Latvian language is one of the two living Baltic languages that is characterized by a complex morphology and syntax. In Latvian, nouns and adjectives have gender, number, and case; verbs have voice, tense (past, present and future), mood; and they can be inflected depending on person and number (Lingvopedia). Chinese is an analytical language characterized by a relatively frequent use of function words, auxiliary verbs, and changes in the word order (Lian, 1993: 1). It is proved by the contrastive analysis hypothesis $(\mathrm{CAH})$ that the knowledge about this difference is very important for teachers who teach Chinese as a foreign language (Ellis, 1986: 22). Latvian researchers 
(Šmits, 1936; Baltgalve, 2015: 230-244) prefer to focus on Chinese literature, culture and religion; and that is why there are so few papers in comparative studies of the Latvian and Chinese languages (Liu, 2015: 301-320; Liaci, 2015: 380-390; Gajevskis, 2019: 286-318). Most of the previous teachers from China (He, 2000: 16-21; Peng and Zhang, 2001: 89-92) who worked in Latvia focused on the general teaching situation; and only a few of them have done research (Jin, 2015: 250-300; Huang, 2015: 390-450; Wu, 2019: 206-221) from a micro-perspective.

The objective of this paper is to find out grammatical errors in written compositions by Latvian students of Chinese as a Foreign Language(CFL) students that are encountered in the process of learning the language. This paper is trying to answer the following questions: (1) Which are the main categories of students' errors? (2) What is the cause of their errors? (3) How and which strategies should teachers and students apply to correct them?

The main aim of the article is to make suggestions regarding new and useful teaching strategies.

\section{Theoretical background and literature review}

The Contrastive Analysis Theory was unable to explain all errors in the language learning process; and some of the predicted errors did not even occur in practice (Allwright and Bailey, 1991). That is why there was a shift to the theory of Error Analysis (EA) in the late 1960s and early 1970s that focused on systematic violations of patterns by learners. Such errors clearly show the influence of the interlanguage used in classes and the level of the acquired knowledge about the language rules studied (Corder, 1981: 46-55). They indicate how far the study process has progressed towards the goal and provide the evidence of ways how the language is studied. Besides, they also illustrate the errors as a device which students unconsciously use to improve their level (ibid.:74). Hendrickson (1987: 357) maintains that errors are a 'signal' that shows intense study process and competence level of the learner regarding the target language structure. Even language teachers find it very difficult to differentiate between 'errors' and 'mistakes', for they are making consistent corrections of these two terms. "An "error" is a deviation from accuracy or correctness. A "mistake" is an error caused by a fault: the fault being misjudgment, carelessness, or forgetfulness.' (Robinson, 1995: 150) Generally people already have an idea of a correct standard of language usage to be able to judge what is wrong and what is right. This standard could also be set by rating or systematizing of errors.

Error typologies are illustrated by different scholars. Researchers distinguish between two types of errors: 'Performance errors are those errors made by learners when they are tired or hurried; while competence errors reflect inadequate learning' (Gefen, 1979: 16-24). Touchie (1986: 75-80) was 
the first to briefly mention major types of errors tracing second language learning errors to both 'inter-lingual' and 'intra-lingual' ones, the former being caused mainly by the interference of their mother tongue. Burt and Kiparsky (1978: 73) distinguish between 'local' and 'global' errors. 'The local errors do not hinder communication and understanding the meaning of an utterance while global errors interfere with communication and disrupt the meaning of utterances. Larsen-Freeman and Michael (1991: 58-59) in their summary of intra-lingual errors identify four types: 'over-generalization, simplification, communication-based errors, and induced errors'. According to the form, there are several basic types: 'omissive, additive, substitutive or related to word order'. They may also be classified as 'phonological errors, vocabulary or lexical errors, syntactic errors, and so on'. Lu (1994: 47) divides errors into four categories: 'omission (yilou), addition (wujia), wrong selection of words (wudai), and wrong word order (cuoxu)'.

However, nowadays even the influence of EA begins to fade. Some critics are concerned about the fact that some teachers judge students' language performance only in terms of accuracy, while the complexity of expressions and speaking fluency can suffer. Many scholars work more on matters related to the differentiation of errors and mistakes, causes of errors, and particularly, the influence of linguistic transfers. In this sense, EA has never totally disappeared from the language learning scenario, continuing to be a more widespread practice than it is considered to be (Jame, 1998: 18). Cook (1993: 2) defines EA as a 'methodology for dealing with data rather than a theory that explains the process of L2 acquisition.' However, despite all the criticism, EA remains widely used because it has proven to be an effective approach for analyzing L2 learners' errors.

\section{Methods}

The article is based on the case study approach and on the statistical analyses. The author collected written compositions of 30 second year undergraduates who major in Chinese as a foreign language at the University of Latvia. of They all had studied Chinese for one and a half year. The textbook they use at the moment is HSK Standard Course 3. Students have completed HSK Standard Course 1 and HSK Standard Course 2 and have also passed HSK 2 exam. HSK Standard Course 1 is mainly about the basic language elements in Chinese, such as the pronunciation and Chinese written characters; HSK Standard Course 2 focuses on the vocabulary expansion and basic communication topics. HSK Standard Course 3 covers basic grammar rules.

For the accuracy of the survey, all assignments were selected only from students whose native language is Latvian. Students were given a written assignment of a text composition with min.100,000 Chinese characters. Firstly, all their errors were divided into four categories, 319 sentence 
examples were elected in total. These errors are all syntactic ones, and most of them occur in simple sentences. Secondly, questionnaires were made in order to gather opinions and to understand the motivation of students, their methods, goals, strengths and weaknesses in learning the Chinese language.

\section{Results and discussion}

\section{Data Analysis}

The data analysis shows that the distribution of four types of errors (wrong word order, wrong selection of words, addition of words, and omission of words) are as follows.

\section{Table 1 Distribution of the four error types}

\begin{tabular}{|l|l|l|l|l|}
\hline & $\begin{array}{l}\text { Wrong } \\
\text { order }\end{array}$ & $\begin{array}{l}\text { Wrong } \\
\text { selection }\end{array}$ & Addition & Omission \\
\hline Frequency & 107 & 109 & 43 & 60 \\
\hline Percentage & 33.50 & 34.20 & 13.50 & 18.80 \\
\hline
\end{tabular}

As it can be seen from Table 1, errors of wrong sentence structure and wrong usage of words are the most wide-spread ones. The most common errors among wrong uses are the following: of 'shi (to be)', of complements, order of prepositional phrases and adverbs, omission of location words, of detachable words, and of synonyms.

(1) Wrong use of the copula 'shi (to be)'

Students often use 'shi (to be)' in the wrong way. There is a structure called adjectival predicate where subject + predicate (adjective) or subject + adverbial + predicate is used without 'shi (to be)'. This kind of error also appears in cases when the adjective is used as an attribute to describe the noun, e.g.:

Example 1. Water is too heavy.

Shui shi taizhong le. (wrong addition of 'shi')

Shui tai zhong le.

Example 2. I am a very smart person.

Wo hen congming de ren. (omission of 'shi')

Wo shi hen congming de ren.

Example 3. It is complicated due to the difference between the two countries. Fuza yinwei liangge guojia buyiyang. (omission of 'shi')

Fuza shi yinwei liangge guojia buyiyang.

(2) Wrong use of complements 
A word or a phrase attached to the verb or an adjectival predicate to complete the meaning of the verb in Chinese grammar is called a complement. Complements are post-modifying elements to show duration, quantity, degree, result, direction or a possible action. In Chinese the complements is always places after the verbs'(Li and Cheng, 2008:7). Students often put complements in a wrong place which is due to the different usage or their absence in their mother tongue, e.g.:

Example 4.

Every day she looks into the mirror for a long time.

Ta meitian henchangshijian zhao jingzi. (wrong word order, the place of 'zhao' and 'henchangshijian'should be changed)

Ta meitian zhao henchang shijian jingzi.

Quite often students also omit some complements, for example, complements of results and complements of direction.

Example 5.

She walked into the post office.

Ta zou youju lai le. (omission of 'jin')

Ta zou jin youju lai le.

(3) Wrong order of prepositional phrases and adverbs

Most of the prepositions have to take a noun or pronoun to form a prepositional phrase to serve as an adverbial adjunct, complement or attributive. 'The modifier, be it attributive or adverbial must be placed before the modified word'( $\mathrm{Li}$ and Cheng, 2008:7). Mono-syllabic adverbs are often used wrongly, especially in compound sentences, e.g.:

Example 6. I want to watch a movie, also my friend wants to .

Wo yao kan dianying, ye wo pengyou yao qu. (the order of the words 'wo pengyou' and the adverb 'ye'should be changed)

Wo yao kan dianying, wo pengyou ye yao qu.

A prepositional phrase is formed by a preposition and an object also in the Latvian language. However, students tend to put the prepositional phrase in a wrong place, e.g.:

Example 7. He bought a ticket in the internet.

Ta mai le piao zai wangshang. (the order of the words 'mai le piao'and 'zai wangshang'should be changed)

Ta zai wangshang mai le piao.

(4) Omission of location words

A phrase indicating the location is a kind of endocentric phrase and has a fixed order of words. It indicates the place, position, time or quantity. The first constituent of the phrase may be a noun, a pronoun or a phrase, while 
the second one shows the location. Students tend to omit words of location when they make sentences, e.g.:

Example 8. The snow fell down from the branch.

Xue cong shuzhi diaoxiaqu le. (the word of location'shang' is missing)

Xue cong shuzhi shang diaoxiaqu le.

(5) Wrong use of detachable words

Detachable words can also be called separable verbs which refer to a group of verbs that can be used as a compound verb or can be separated and used as a verb-object (VO) phrase (also called separable VO phrase). Because of this seemingly strange grammatical definition, students often use them in a wrong way, e.g.:

Example 9. They talked a lot of words.

Ta men liaotian le henduo hua.(the object 'tian' is not necessary because here the object is 'henduo hua')

Ta men liao le henduo hua.

(6) Wrong use of synonyms

Due to the lack of appropriate dictionaries, it is rather impossible to find dictionaries of synonyms that help to distinguish among them. So students frequently make mistakes, especially when doing translation homework, e.g.: Example 10. We went there to eat and used chopsticks.

Women qu na'er chifan, he yong kuaizi.(wrong use of the copula 'he(and)' as it is used with nouns, not with verbs)

Women qu na'er chifan, yong kuaizi.

Example 11. The conductor pats him and says.

Liechezhang pai le ta he shuo.(wrong use of the word 'he(and)', 'bing' is used for connecting two verbs)

Liechezhang pai le ta bing shuo.

\section{Causes of errors}

In the $10^{\text {th }}-12^{\text {th }}$ centuries, there were many dialects in Latvia that later formed the standard Latvian language. Only in 1918, after the gaining of independence, Latvian became the official language. Due to the historical background, Latvian has been influenced by many other languages. One can observe the influence of the German pronunciation, the influence of the Russian vocabulary. A big impact came from the Finno-Ugric languages, therefore 'In general, Latvian has the stress on the first syllable of the word,' (Praulinš, 2012: 1-6). Corder (1981: 97-98) argues that in the process of language studies second language learners have acquired their own 'built-in syllabus', and their errors are a concrete manifestation of this 'inherent 
outline'. There are two main reasons for this: the direct transfer of the mother tongue and insufficient knowledge of the target language. The Latvian language has a free word order thanks to the category of the case of nouns. For example:

Example 12. Kakis ēda peli. (The cat ate the mouse.)

Peli êda kak,is. (The mouse was eaten by the cat.)

Mao chi laoshu.

The meaning of both sentences in Latvian is the same, and the subjectobject distinction is made basing on the case of the noun. However, if we change the word order in Chinese (or in English), the meaning can become reverse. In Latvian, the subject need not be at the beginning of the sentence, because the gender and number of the subject can be determined by the endings, those of verbs and adjectives including. Personal pronouns are only used if they need to be stressed, and it is quite common to omit them (Praulinš, 2012: 52). It is not possible in Chinese. Chinese nouns can function as verbs (Lian, 1993: 46), but not possible in Latvian (Praulinš, 2012: 1-6). Latvian students sometimes put the subject in the wrong place in Chinese, especially in more complex sentences. A Latvian sentence must have a predicate, and it can take the initial position, but in Chinese, there should always be a subject (or subject phrase) that opens a sentence. Latvian students tend to omit the subject:

Example 13. Ir (predicate) loti interesanti mācīties ķīniešu valodu.

(It (subject) is (predicate) very interesting to study the Chinese language.)

Youyisi xuexi hanyu.( wrong word order)

Xuexi hanyu youyisi.

The adverb 'hen (very)' can have a predictive function in Chinese, so it is used before adjectives instead of the verb 'be'. A Latvian sentence always needs a predicate (i.e. a verb), e.g.:

Example 14. Viņš ir l̦oti draudzīgs. (He is very friendly.)

Ta shi hen youshan.(wrong addition of 'shi')

Ta hen youshan.

In Chinese, the propositional phrases are mainly used as an adverbial adjunct to premodifying the verb predicate always precede the head word ( $\mathrm{Li}$ and Cheng, 2008:123). Errors in Example 15 are caused by a transfer of usages in the mother tongue, because students cannot get easily used to the Chinese word order, such as:

Example 15. Es studēju Latvijā. (I study in Latvia.)

Wo xuexi zai latuoweiya. ( the order of the words 'xuexi' and 'zai latuoweiya' should be changed)

Wo zai latuoweiya xuexi.

Due to the direct transfer of the mother tongue, many people will speak in a foreign language the same way they think in their own language. They 
will inevitably ignore the word order. Such errors occur very often because the wrong word order does not always affect the meaning and corrections are not essential for making the utterance to be understood. Another reason for the wrong word order can also be a literal translation, if students only pay attention to lexical correspondence and do not consider the word order in Chinese, e.g.: Example 16. Pērn es pusgadu mācījos kādā valodu skolā.

(Last year I studied at a language school for half a year.)

Qunian bannian xuexi le zai yuyan xuexiao.( the order of the words 'xuexi le'and 'banian'should be changed)

Qunian wo zai yuyan xuexiao xuexi le bannian.

In the late 1960 s, scholars began to pay more attention to the influence of the 'interlanguage' that often sustains the whole learning process. Both the source language and the target language influence differently. Thus, in addition to the wrong transfer of the mother tongue, the ignorance of rule restrictions and over-generalization are the two major negative aspects (Selinker, 1972: 209-241). For example, the complement in Latvian represents the second component of the VO (the first being the declination of the object noun). Therefore it is easy for Latvians to omit the result complement mark 'dao (to)' after the verb. Prepositions of direction (such as 'dao (to)' in Chinese) are easily omitted because analogous Latvian verbs can be followed by a direct object without prepositional structures, e.g.:

Example 17. Mēs sajutām kādu smaržu. (We smelled some aroma)

Women wenle yizhong weidao. (omission of the preposition 'dao')

Women wendao le yizhong weidao.

Another common error occurs due to wrongly indicating the direction towards or away from the speaker. In English the direction towards the speaker can be expressed with the verb 'to come', and the direction away from the speaker - with the verb 'to go' ('nākt' and 'iet' respectively in Latvian) The verb structure consists of the same verb and the same direction complement for 'come' or 'go' in Chinese. They also have approximately the same meaning, so there are not many mistakes regarding this, e.g.:

Example 18. We came back. Mēs atnācām atpakaḷ.

Women huilai le. (the direction towards the speaker)

Example 19. We went back. Mēs gājām atpakaḷ.

Women huiqu le. (the direction away from the speaker)

However, in Chinese, verbal phrases may consist of many separable parts and direction of action complements that have no analogues in Latvian, e.g.:

Example 20. Viņš dodas augšā. (He goes upstairs.)

Ta shanglou.(omission of the complement 'qu')

Ta shanglou qu.

Compound complements of direction cause especially many errors. 
There may be a compound after the predicate verb that indicates a dualdirection (in the following example: downwards and to the speaker), e.g.:

Example 21. The doctor told why it had run down here.

Yisheng gaosu ta weishenme pao xia le.(omission of the second complement 'lai' which stands for the direction)

Lang saosu ta weishenme pao xialai le.

Complete omission of the result complement can be observed even more often in students' homework. Taylor (1975: 73) wrote:

'The results indicated that the errors made by the elementary and intermediate students were not qualitatively different. However, the subjects' reliance on the strategies of overgeneralization and transfer was found to be qualitatively different. The elementary subjects' reliance on the transfer strategy was found to be significantly higher than that of the intermediate subjects; the intermediate subjects' reliance on the overgeneralization strategy was found to be significantly higher than that of the elementary subjects.'

This kind of problem is related to the teacher's knowledge of Chinese ontology, and especially to the depth of the teacher's understanding of Chinese ontology and grammar. According to theoretical studies of the secondlanguage acquisition, these errors are mostly caused by the learner's method of reasoning and by the inappropriate use of the newly acquired target language. In order to pursue the efficiency of learning, students and teachers often reckon that they use 'almost the same' argumentation and explanation. But in fact, there are big differences. For example, misunderstanding of some synonyms often appears during the teaching and learning process:

Example 22. Wo renwei diu le wo de zixingche.

I thought I had lost my bike.

Wo yiwei diu le wo de zixingche.

I (mistakenly) thought I had lost my bike.

The error in the translation of this example is due to the fact that only the English word 'think' is used when translating the Chinese words 'yiwei' and 'renwei'. In fact, the English word 'think' corresponds to three different Chinese words: 'yiwei(to think, usually there is an implication that the notion is mistaken-except when expressing one's own current opinion.)', 'renwei(to think; to believe)', 'juede(to think; to feel)'. So, when students do not understand the difference between them, the knowledge generalization occurs. Of course, the generalization has a strong relationship with the study of Chinese ontology. The main basis for our judgment of grammar is the sense of language. Zhou (2003: 53-57) and Zhang (2007: 24-25) who teach Chinese as a foreign language, have been focusing on the study of the Chinese language 
sense model, and they attach great importance to the cultivation of the language sense.

Other reasons for the error occurrence are related to cultural factors native and foreign mentality, the way of learning and communication, influence of attitudes. Sometimes one can also observe the phenomenon of inappropriate and inadequate explanation and training of the target language by teachers and in textbooks. However, most of the errors mentioned in this article were taken from students' compositions; and the analysis focused more on the linguistic part than on cultural or other differences.

\section{Error correction strategies}

At present, people are more and more aware that a successful language teaching should have two foundations: the study of the target language and the research of students' learning process. The effectiveness of studies has a close connection with students' aptitude, personality, motivation, and cognition of learning as such. The study of the target language (in this case: Chinese) is also part of studying Chinese ontology, so the error problem could be solved in three ways: comparing and understanding differences between Latvian and Chinese, observing and adapting to students' characters, improving teaching strategies.

There are also many syntactic similarities between Latvian and Chinese. Sentence patterns of existence and appearance show similar word order in both languages (while they may differ in Chinese and English), e.g.:

Example 23. Šeit ir četras grāmatas. (There are four books here.)

Zheli you siben shu.

Some Latvian interrogative pronouns can also be used as indefinite pronouns, e.g., 'kāds' can mean 'what' or 'some/ somebody/ someone'; 'kas' can mean 'that', 'what', 'who' and 'something'. This is not the case in Chinese. Comparative study of Chinese and Latvian is surely a very broad subject, and in the future there should be more researchers in this field.

Learners whose mother tongue has a complex syntactical and morphological system often have no difficulties learning grammatical forms in other languages, while learners whose mother tongue has a simpler grammatical system find it hard to learn another grammatically complex language. Therefore, Latvian students do not consider Chinese grammar to be difficult. In the questionnaire, 30 Latvian students had to choose two most difficult language elements; and their answers are given in Table 2: 
Table 2 Difficulty rating of language elements

\begin{tabular}{|l|l|l|}
\hline & $\begin{array}{l}\text { Frequency of } \\
\text { difficulties }\end{array}$ & Percentage of difficulties \\
\hline 1. Chinese characters & 21 & 70 \\
\hline 2. Phonetics & 18 & 60 \\
\hline 3. Vocabulary & 14 & 46.6 \\
\hline 4. Grammar & 7 & 23 \\
\hline
\end{tabular}

Chinese characters are the most difficult part, followed by pronunciation, and only then by vocabulary and grammar.

In addition to the above survey data from students, the author of the paper recorded some personal observations during the work at the University of Latvia (three years in the period from 2013 until 2019). Interviews with three local Chinese language teachers (Agita Baltgalve, Karina Jermaka, Julija Gumilova teach Chinese at the University of Latvia and specialize in Chinese Studies) were conducted as well. The results are summarized below.

Students who study Chinese in Latvia are mainly girls. In Latvia, the gender ratio is unbalanced. The language learning is inherently advantageous for girls because, for example, the writing of Chinese characters requires great patience, so the number of males is very small (see Table 3). Females show more patience in language studies.

\section{Table 3 Gender ratio}

\begin{tabular}{|l|l|l|}
\hline & Number of persons & Percentage \\
\hline Total & 30 & 100 \\
\hline Female & 27 & 90 \\
\hline Male & 3 & 10 \\
\hline
\end{tabular}

Latvians are very introverted and shy to express themselves or perform in front of the public. Some students are very shy and teachers need to get really familiar with them beforehand. It needs some time for students to feel comfortable in the teacher's presence. After some time students will communicate with the teacher without feeling awkward or shy, however, the familiarization process may take three to six months.

Students have a good visual memory. It is rather easy for Latvian people to study Chinese characters individually at home. They have a strong hands-on experience, so their skills for writing Chinese characters are good. 
However, there still may be some omissions or wrong additions of strokes. The ability to write Chinese characters is inseparable from the strong handson training of Latvian youngsters from an early age. This factor gets well coupled with their introverted personality; that is why many students prefer quiet writing activities. Most learners are multilingual. Grammar rules of the languages they know already are more complicated than those of Chinese. Therefore, the grammar of the Chinese language generally does not seem too difficult for them, but there are still many problems regarding word order and vocabulary usage.

Some students do not study regularly because they have to work in order to earn money for the tuition fee. It requires teachers to prepare a large number of additional teaching materials to assist them in their studies. After some time, students who are in one group may have quite a different language proficiency level; and some may need an individual instruction.

Whether errors should be corrected instantly and in what way they should be corrected here opinions of researchers differ. Some scholars believe that errors should be corrected immediately, and that teachers should systematically summarize and explain them. However, others maintain that errors are a natural element in the learning process. During foreign language studies, students slowly form a dynamic apprehension mode that is a kind of system between their mother tongue and the target language. Corder (1981: 15-25) maintains that 'any sentence they say has a grammatical relative to the learner's own language', he calls it an 'idiosyncratic dialect'. The author of this article fully agrees with this kind of an 'interlanguage'. Foreign language skills go through a process of natural development; and students achieve selfimprovement and completeness in this cognitive development. Regarding errors, the teaching strategy can include four aspects:

-prediction of errors;

-correction of mistakes by the teacher and self-correction;

acceptance of errors as part of the language learning process and creation of an open attitude towards learners;

- development of an emotional trust with and among students in order to achieve and experience a more pleasant attitude towards the correction of errors.

Teaching Chinese as the second language, one should pay special attention to students' comprehension of word order and should engage them in diverse language learning activities in the classroom, such as asking students to make a sentence with words given in a mixed order and gradually increasing sentence length for advanced level learners.

At present, in second language acquisition, more and more researchers emphasize the role of non-intellectual factors, such as attitude, motivation, or personality of learners. There is still a lot of room for improvement. For 
example, local Chinese teachers can develop the same empathy as foreign students. Chinese teachers can try to understand psychological feelings of students when they learn a foreign language, and then they will understand the abilities of students at definite stages of language learning much better. Of course, it is also very important to use adequate methods to teach Chinese at different levels. At the beginner level, the teacher should use a lot of gestures, pictures, cards, etc., because a strong connection between the sound and meaning must be established due to the limited language competence of students. Teachers also need a rigorous teaching strategy that would motivate students to adapt to the respective teaching style and to become familiar with the teaching mode in order to follow, listen, read, and write.

In fact, there are also many errors in pronunciation and writing Chinese characters. But this article was mainly based on the analysis of grammatical aspects. The author highlighted only some types of errors; however, it is not yet clear which types of errors can be avoided by repeated practice in a short period of time, and which ones will take a longer time to be eradicated to reach automatic use. In order to get more accurate data, these aspects still need a further dynamic observation and experimentation.

\section{Conclusion}

The analysis has proven that errors of wrong sentence structure and wrong usage of words are the most wide-spread ones. Among them, the most common errors are the wrong use of 'shi (to be)', wrong use of complements, wrong order of prepositional phrases and adverbs, omission of location words, wrong use of detachable words, and wrong use of synonyms. At the same time, it was found out that a direct transfer of the mother tongue is the main reason to cause errors in the word order. Students often ignore special grammatical aspects of the word order in the Chinese language. Errors of word usage are mainly caused by the generalization of the knowledge both in teaching and learning. Therefore, a serious attention should be paid to these kinds of errors, offering solutions, such as prediction of mistakes, correction of mistakes and self-correction. One should maintain an open-minded attitude towards grammar mistakes and accept them as part of the language learning process. Besides, teachers should establish an emotional trust with students in order to have a more pleasant experience correcting their errors and mistakes 


\section{References:}

1. Allwright, D. and Bailey, K. M. (1991) Focusing on Language Classroom. London: Cambridge University Press.

2. Baltgalve, A. (2015) A Review of Sinology Research in Latvia (Latuoweiya Hanxue Yanjiu Shuping). Research of Chinese teaching in Latvia : 230-244.

3. Burt, M. K. (1975) Error analysis in the adult EFL classroom. TESOL Quarterly, 9: 53-63.

4. Burt, K.M. and Kiparsky, C. (1974). The Gooficon. Rowley, MA:Newbury House Publishers.

5. Corder, S. P. (1981) Error Analysis and Interlanguage. Oxford: Oxford University Press.

6. Cook, V. (1993) Linguistics and Second language Acquisition. London: The Macmillan Press LTD.

7. Ellis, R. (1986) Understanding Second Language Acquisition. $2^{\text {nd }}$ Improved Edition. Oxford: Oxford University Press.

8. Gefen, R. (1979) The analysis of pupils' errors. English Teachers' Journal, 22, 16-24.

9. Gajevskis, E. (2019) Study of Noun Measure Words in Teaching Chinese to Latvian Students (Latuoweiya Xuesheng Hanyu Mingliangci Pianwu Jijiaoxue Duice Yanjiu).

10. Research of Chinese teaching in Latvia: 286-318.

11. Hendrickson, J. M. (1987) Errors correction in foreign language teaching: Recent theory, research, and practice. In: M.H. Long \& J.C. Richards (Eds.), Methodology in TESOL: A book of readings. Boston: Heinle \& Heinle.

12. He, J. (2000) Chinese teaching in Latvia University (Latuoweiya de Hanyu Jiaoxue). Journal of Chinese Teaching in the World. No.2: 2429

13. Huang, Y. (2015) Chinese learners'acquisition errors and teaching strategies of noun measure words in Latvia (Latuoweiya Hanyu Xuexizhe Mingliangci Xide Pianwu Jijiaoxue Celue). Research of Chinese teaching in Latvia: 390-450

14. Larsen-Freeman, D. and Michael H. L. (1991) An introduction to second language acquisition research. New York: Longman.

15. Liu, A. (2015) The research on teaching Russian students the Chinese Language phonetics (Dui Muyu wei E'yu de Xuesheng de Hanyu Yuyin Jiaoxue Yanjiu). Research of Chinese teaching in Latvia : 301320 
16. Liaci, A. (2015) An Analysis of Errors by Latvian Native Speakers During their Acquisition of Chinese Existential Sentence with 'you' (Latuoweiya Muyuzhe Xuexi Hanyu 'you' Cunzaiju Pianwu Jifenxi). Research of Chinese teaching in Latvia: 380-390.

17. Lian, Sh. (1993) Contrastive studies of English and Chinese (Yinhan Duibi Yanjiu). Beijing: Peking higher English education publishing house.

18. Lu, J. (1994) Grammatical error analysis of foreigners learning Chinese (Waiguoren Xuexi Hanyu de Yufa Pianwu Fenxi). Language Teaching and Linguistic Studies, No.1: 46-60.

19. Li, D.and Cheng,M.(2008) A practical Chinese grammar for foreigners (Waiguoren Shiyong Hanyu Yufa).Beijing:Beijing language and culture university publishing house.

20. Praulinš, D. (2012) Latvian:An essential Grammar. USA: Routledge.

21. Peng, F.and Zhang, H. (2001) The Recent Chinese Teaching in Latvia (Latuoweiya Hanyu Jiaoxue de Jinkuang). Journal of Yunnan Normal University (Humanities and Social Sciences Edition), Volume 9 No.5: 89-92

22. Richards, J. C. and Schmidt, R. (2002) Dictionary of language teaching and applied linguistics (3rd Ed.). London: Longman.

23. Selinker, L. (1972) Interlanguage. International Review of Applied Linguistics, 10: $209-241$.

24. Shastri, P. D. (2010) Communicative approach to the teaching of English as a second. Language (pp. 26-27). Mumbai:Himalaya Publishing House.

25. Šmits, P. (transl.), (1936) Kìniešu pasakas. Rīga.

26. Taylor, Barry, P. (1975) The use of overgeneralization and transfer learning strategies by elementary and intermediate students of ESL. Language Learning, 25(1): 73 - 107

27. Touchie, H. (1986) Second Language Learning Errors. Their Types, Causes, and Treatment. JALT Journal, volume 8, No. 1: 75-80.

28. Wu, W. (2019) Research of Teaching Chinese Tones to Russian students in Latvia (Latuoweiya Ezu Xuesheng Hanyu Shengdiao Jiaoxue Yanjiu). Research of Chinese teaching in Latvia: 206-221

29. Zhang, W. (2007) Language intuition training is the basic task of teaching Chinese as a foreign language (Yugan Peiyang shi Duiwai Hanyu Jiaoxue de Jiben Renwu). Chinese teaching in the world No.3.1: 24-25.

30. Zhou, J. (2003) Teaching Chinese as a Second Language Should be Guided by Developing Learner's language Intuition (Di'er Yuyan Jiaoxue Yingyi Peiyang Yugan wei Daoxiang). Language and Translation No.1: 53-57. 


\section{Internet Sources}

1. Lingvopedia: Latvian (Latviešu valoda). (2020) The Project: Lingvo.info (supported by the European Commission of Lifelong Learning Program). Available from https://lingvo.info/en/lingvopedia/latvian [Accessed on 2 November 2019]

2. Robinson, P. (1995) In the matter of the gate keeper: the gate contracts. Available from https://tvtropes.org/pmwiki/pmwiki.php/Literature/TheGatekeeper [Accessed on 2 November 2019] 